\title{
FOCUS AWARDS 2002
}

(DH) Department
of Health
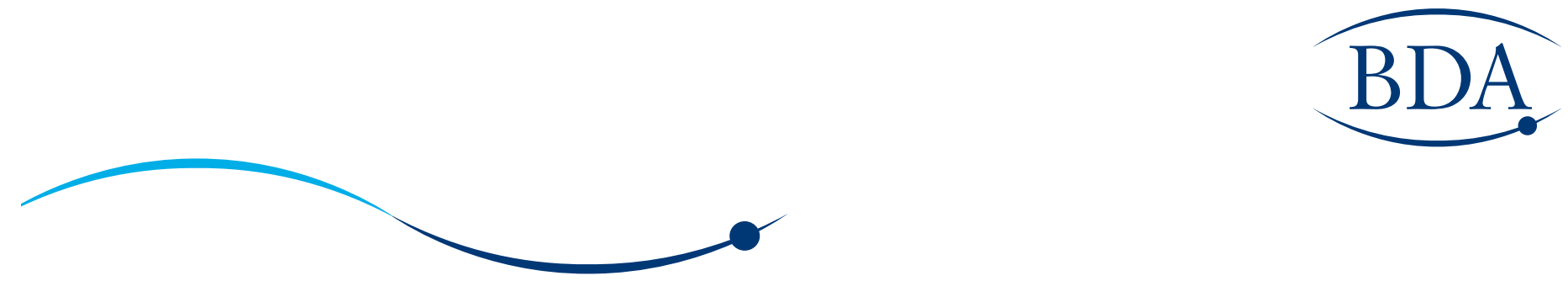

The treatment adviser at the Clock House Dental Practice thought that their patient services had improved so much over a very short time that she decided to nominate the practice for the Focus Awards Prize.

Six years ago, Andrea Ubhi took over a closed-down practice in the village of Heworth and moved it to a new premises: the Clock House Dental Practice was born and the staff and patients haven't looked back. There have been many innovations introduced to the way the practice works and all of them are patient-centered.

So what are they doing at the Clock House that has made such a difference?

- Hired a public relations officer to promote the practice.

- Created a special treatment adviser role.

- Employ hi-tech diversion therapy.

- Introduced an aftercare call service.

- Ensured full accessibility.

How these work and the difference it makes to the patients are described below.

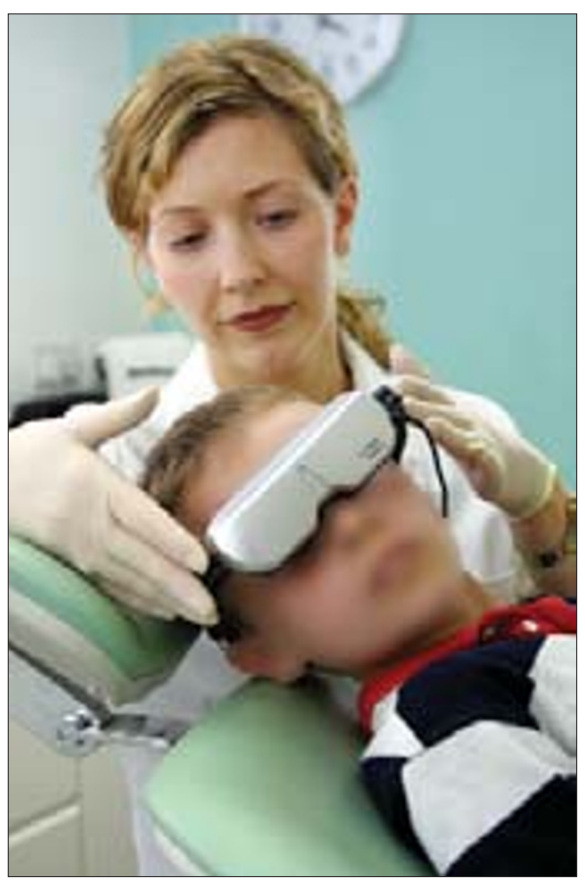

A young patient puts the i-CAM goggles to the test.

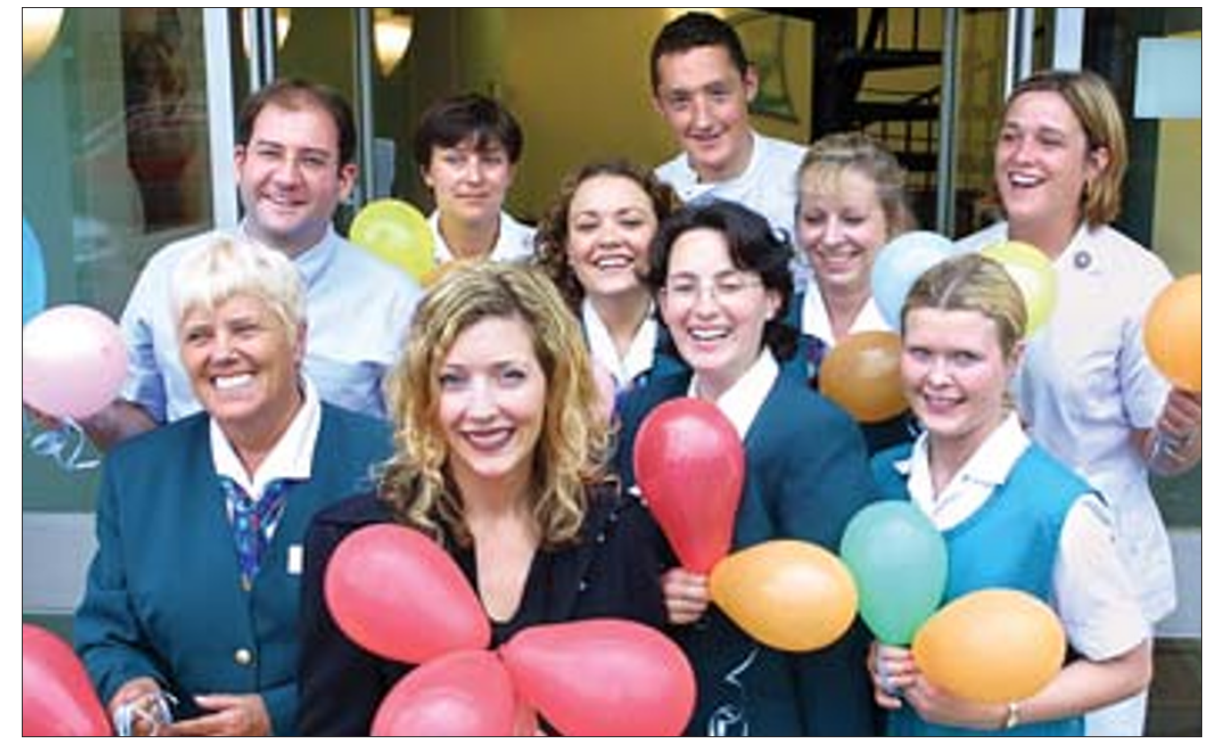

The Clock House Dental team celebrate their success of making it to the final of the Focus Awards.

\section{PROMOTION}

One of the reasons that the Clock House Practice stood out with the judges was their self-promotion. The practice is publicised locally with the help of a public relations officer who is shared with a sister practice. Abigail Crerar, the PR officer, writes press releases and produces posters to put in libraries and doctor's surgeries. These include information such as a local bus timetable so that people from the surrounding villages know that they can get to the practice on public transport. It all helps to raise the profile of the practice and lets people know they have an NHS practice in their area. They also use topical things like Mouth Cancer Awareness Week to get people aware of oral health. The press releases really work, Abigail explains, 'There is always a surge of response after we have been in the local press. It is great to get in the local paper but it is so much better when you get a patient response.' Very often new patients say that they found out about the practice in the newspaper.

\section{SPECIAL ROLE}

One of the most interesting innovations is the introduction of the treatment adviser role. Rosemary Taylor has worked locally in dentistry for 18 years and has built up strong relationships with the community. This tie with the patients is such, that they used to stop her in the local supermarket and ask advice on the treatment they were receiving. So Andrea Ubhi, the practice principal, decided to use this level of trust to the advantage of both the patient and the practice. Rosemary was made Treatment Advisor, and now all patients who wish for advice go to see Rosemary. With her they can discuss their treatment options, see 'before and after' photographs for different treatments, and generally chat about any worries that they might have. This works well for the patients because they feel more relaxed talking to Rosemary than when talking to a dentist and find it easier to ask questions. It works well for the dentists too because it means they can see more patients. 


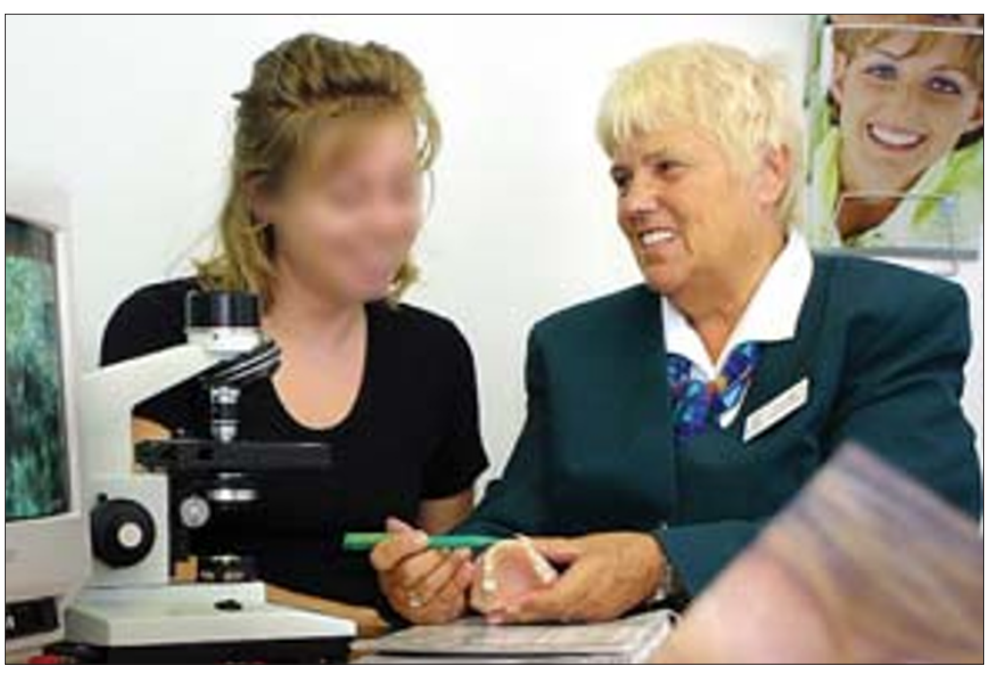

Rosemary, Treatment Adviser, talks a patient through her treatment plan.

\section{HI-TECH DIVERSION THERAPY}

When the patients arrive for their treatment there is a range of audio-video equipment to help divert them, particularly if they have to be in the chair for a long time. These include i-CAM DVD goggles and earpieces so patients can watch films and comedy programmes or listen to music. They can adjust the volume to drown out the sound of the drill or leave an ear free to hear what the dentist is saying to them. 'The patients think it is great' says Rosemary, 'we get lots of really nice comments.'

\section{AFTERCARE}

The Clock House Dental practice has a very comprehensive aftercare service. Once a patient has had some treatment or surgery, someone from the practice telephones them to see that they are well and to offer advice. Usually it is the nurse who calls the patients, again because people often find it easier to talk to the nurse, but depending on the type of surgery involved, the dentist might make the call. This gives the patient the opportunity to ask any questions that have occurred to them since having the surgery. This further contact with the practice after a procedure can be very reassuring, particularly for nervous patients or those who have undergone a major procedure.

\section{ACCESS}

The Clock House premises are totally accessible to those with mobility difficulties, even the two small steps that lead to the entrance have a portable wheelchair ramp that is arranged on the days that it will be needed. The reception desk is also at split-level so that wheelchair users can use it too.

All of these ideas and innovationsmake the patient's trip to the Clock House Dental a relaxed and friendly experience.

Naomi Davis
The Focus Awards is a joint initiative between the Department of Health of England and the British Dental Association. It was set up to recognise and celebrate the innovative patient-focused projects being carried out across England.

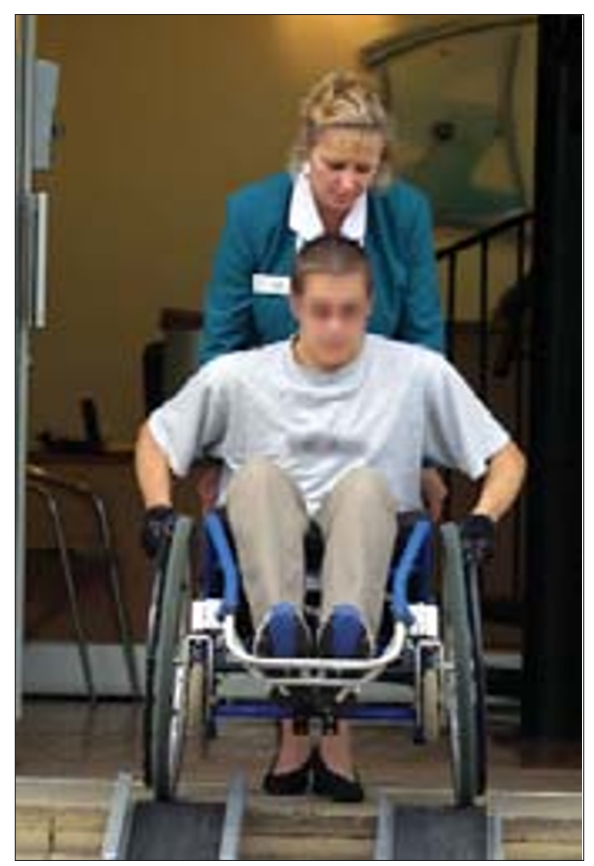

The wheelchair ramp in use.

\section{How the practices got involved}

In order to participate, each entrant had to submit a nomination form specifying the innovations under the categories given below. Any practice that had applied last year was not allowed to use the same innovations in their application.
- Patient's experiences contacting the practice/clinic before, during and after treatment.

- Patient's experiences whilst in the reception or waiting area

- Patient's experiences during clinical treatment

- General communication with the patients

- Any other patient-focused innovation 